\title{
Lila Luchessi y Luciano Videla Luciano (compiladores) \\ Desafíos del periodismo en la sociedad del conocimiento.
}

Viedma, Argentina: Universidad Nacional de Río Negro, 2016. 122 p. (Congresos y jornadas). ISBN 978-987-3667-29-9

Este libro demuestra el trabajo conjunto entre académicos y periodistas mediante la coordinación de profesionales argentinos y brasileños. Se recopilan en él reflexiones basadas en la actualidad de la profesión periodística y en los medios y sistemas de comunicación dentro una sociedad que se ha transformado en prosumidora, en la que las reglas de juego se modifican a pasos agigantados. Es el resultado de los temas tratados en el tercer Seminario Brasil Argentina de Pesquisa em Jornalismo (BAPIJOR), realizado en abril de 2014 en la sede Atlántica (Viedma) de la Universidad Nacional de Río Negro. Fue publicado por la editorial UNRN - enmarcados bajo la colección Congresos y jornadas - en dos versiones: formato de libro impreso y archivo digital (que puede descargarse gratuitamente de www.editorial.unrn. edu.ar).

El periodismo está cambiando (ya lo hizo y lo seguirá haciendo). La nueva realidad de la profesión trae consigo un juego político complejo en el que la batalla por la agenda conlleva intereses concretos que no deben ser ignorados. Frente a esto los compiladores afirman: "Las discusiones sobre la política, la ética, las economía de las empresas y la acción del periodismo en la sociedad del conocimiento plantean desafíos urgentes y compromisos democráticos" (p. 10).

Entran en juego criterios como el rol actual del periodismo, profesión cada vez más inestable y precarizada; de los periodistas como profesionales que luchan entre la necesidad de publicar con inmediatez y la de investigar, confrontar la información y analizar de la veracidad de los contenidos a publicar; la influencia de la opinión pública, entre otros.

La estructura tradicional de los medios de comunicación también está transitando un camino de modificaciones estructurales profundas y esto trae consigo variadas consecuencias. La condición en la que se encuentra el negocio mismo de la información como bien y el tenso vínculo existente entre las instituciones, los periodistas y los medios de comunicación es un punto fundamental de análisis, reflexión y discusión.

En el libro también se desarrollan estudios específicos sobre la discursividad mediática y los resultados que ésta genera.

Adriana Amado se enfoca en el papel de la información en un ejercicio profesional que ha variado desde el newsroom (centrado en el trabajo de oficina dentro de las redacciones) al cloudsroom (donde las competencias que se requieren han variado de la mano de la sociedad). Afirma: "En ese nuevo cloudsroom se requieren nuevas competencias para producir información con valor agregado, que valore la intervención del periodista y haga transparente la responsabilidad de las fuentes" (p. 20).

El autor Ariel Palacios nos adentra en la compleja realidad de la información que trasciende al mundo comprendido en internet y 
se pregunta si todo lo que se publica es verdadero. Para ello refiere al concepto de "viralización" y al análisis que conllevó la Ley Argentina de Servicios de Comunicación Audiovisual (Ley 26.522).

No solo examina el desarrollo de la ley de medios, sino que se centra lo que se dijo $y$, fundamentalmente, lo que no; haciendo mención a la manipulación, simplificación y banalización de conceptos como comunismo, monopolio, dictadura, entre otros.

Por su parte, Martín Becerra estudia las políticas de comunicación producidas durante el período 2003-2013 del kirchnerismo, asegurando que estas "alcanzaron un protagonismo inédito en la agenda política y trascendieron el debate especializado de los profesionales y analistas de los medios para nutrir la discusión en el espacio público" (p. 29).

Guillermo Berto reflexiona sobre la publicación de noticias policiales y el papel fundamental que juega el discurso policial como única fuente periodística. Sobre la premisa de que las publicaciones no tienen filtro a la información, sostiene que "[e]l periodismo y las fuentes de información son protagonistas de una puja por el control del discurso público" (p. 51). Analiza las reglas y acuerdos tácitos que existen entre ambos, así como los mecanismos de producción y publicación desarrollados en este contexto.

También, Lila Luchessi refiere a las fuentes, pero lo hace centrándose en su mediatización. Afirma: "las herramientas actuales para la producción noticiosa ya casi no permiten el contacto directo con las fuentes primarias" (p. 59), las cuales, al no ser desinteresadas, poseen un rol relevante debido a su capacidad de brindar información y al doble juego que se produce en el proceso. A su vez, explica el viraje de los medios y las nuevas formas de circulación informativa.

Por otro lado, Fernando Irigaray expone sobre el estado ascendente de la producción de documentales multimedia como forma narrativa híbrida mediante el análisis de un caso específico: Calles perdidas. Sostiene la relevancia de internet y analiza experiencias en las que los conceptos de interactividad, multimedialidad e hipertextualidad resultan ser protagonistas de un sistema de producción en auge.

El texto "Audiencias, participación y periodismo", de Francisco José Castilhos Karam, comienza realizando un recorrido histórico con los objetivos de la comunicación como elemento principal. Como este autor afirma, nos encontramos en un escenario en el que "el periodismo compite con nuevas narrativas, con públicos interesados en contar o repasar historias [...] sin los criterios periodísticos y sin la preocupación acerca de cómo es el lenguaje y, también, sin demasiada atención a la credibilidad y la verosimilitud" (p. 80). Además se pregunta sobre el papel de las audiencias en la sociedad actual y la eficacia de los mensajes, entre otras cuestiones.

Gastón Roitberg se refiere al concepto de prosumidor: los consumidores de noticias también son productores interesados y los periodistas enfrentan el desafío de coproducir con las audiencias. No solo brindan información abierta y directa sino que se ocupan de compartir y hasta "viralizar" las notas publicadas por los medios.

Para esa interacción entre actores, las redes sociales juegan un papel fundamental, puesto que en estas se puede publicar información, promocionar contenidos, testear los intereses y gustos de los usuarios, interactuar, etc. 
Luciano Videla considera el concepto de precarización laboral como un elemento central en el periodismo tanto pasado como actual, basado en un estudio más amplio sobre medios de comunicación de Viedma, Río Negro (y cuyos resultados pueden extenderse a toda la Patagonia).

En primer lugar, efectúa un recorrido histórico (iniciando en los 80) sobre las radios FM y AM de la localidad: mientras que comenzaron a existir cada vez más las FM, las otras iniciaron su progresivo declive y cierre. En segundo término, analiza la evolución del periódico (con la disminución en los costos de producción), lo que conllevó una proliferación de medios gráficos, seguida de su decaimiento hasta llegar a la actualidad, donde solo cuatro - de una extensa lista - lograron sobrevivir. En un tercer grupo, refiere a los medios digitales, al asegurar que así surgió "el webpropietario-fotógrafo-diseñador-publicista-sin oficina-sin horario de cierre" (p. 84). Concluye su exposición dedicando un apartado para reflexionar sobre el rol que posee el Estado en este proceso histórico y mediático.

Finalmente, Rogèrio Christofoletti reflexiona sobre el lugar que ocupa la ética en este contexto mediáticamente cambiante; así busca describir el modo en que esta se presenta en los medios actuales, los profesionales de la comunicación, las audiencias y los sujetos que responden al nuevo criterio de prosumidor.

Acertadamente los autores participantes han dejado abiertos ejes para nuevas y futuras discusiones en lo referente al rol de la profesión periodística, las responsabilidades sociales, profesionales e institucionales y especialmente, el lugar que ocupa la información en un contexto cambiante.

\section{Camila Gorostegui}

Universidad Nacional de Río Negro, Viedma, Río Negro, Argentina camigorostegui@gmail.com 